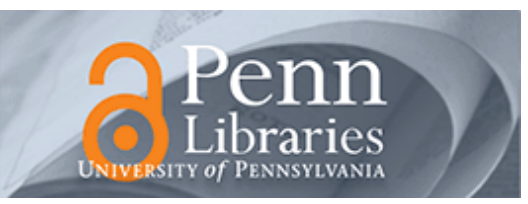

University of Pennsylvania

ScholarlyCommons

4-30-2016

\title{
Self-Care Confidence May be More Important than Cognition to Influence Self-Care Behaviors in Adults with Heart Failure: Testing a Mediation Model
}

Ercole Vellone

Luca Pancani

Andrea Greco

Patrizia Steca

Barbara Riegel

University of Pennsylvania, briegel@nursing.upenn.edu

Follow this and additional works at: https://repository.upenn.edu/nrs

Part of the Behavioral Medicine Commons, Cardiology Commons, Cardiovascular Diseases Commons, Circulatory and Respiratory Physiology Commons, Medical Humanities Commons, Nursing Commons, and the Preventive Medicine Commons

\section{Recommended Citation}

Vellone, E., Pancani, L., Greco, A., Steca, P., \& Riegel, B. (2016). Self-Care Confidence May be More Important than Cognition to Influence Self-Care Behaviors in Adults with Heart Failure: Testing a Mediation Model. International Journal of Nursing Studies, 60 191-199. http://dx.doi.org/10.1016/ j.ijnurstu.2016.04.016

This paper is posted at ScholarlyCommons. https://repository.upenn.edu/nrs/187

For more information, please contact repository@pobox.upenn.edu. 


\title{
Self-Care Confidence May be More Important than Cognition to Influence Self- Care Behaviors in Adults with Heart Failure: Testing a Mediation Model
}

\author{
Abstract \\ Background \\ but further study is needed to validate this finding. \\ Objectives \\ domains and heart failure self-care. \\ Design \\ Secondary analysis of data from a descriptive study. \\ Settings \\ Three out-patient sites in Pennsylvania and Delaware, USA. \\ Participants
}

Cognitive impairment can reduce the self-care abilities of heart failure patients. Theory and preliminary evidence suggest that self-care confidence may mediate the relationship between cognition and self-care,

The aim of this study was to test the mediating role of self-care confidence between specific cognitive

A sample of 280 adults with chronic heart failure, 62 years old on average and mostly male (64.3\%).

Methods

Data on heart failure self-care and self-care confidence were collected with the Self-Care of Heart Failure Index 6.2. Data on cognition were collected by trained research assistants using a neuropsychological test battery measuring simple and complex attention, processing speed, working memory, and short-term memory. Sociodemographic data were collected by self-report. Clinical information was abstracted from the medical record. Mediation analysis was performed with structural equation modeling and indirect effects were evaluated with bootstrapping.

Results

Most participants had at least 1 impaired cognitive domain. In mediation models, self-care confidence consistently influenced self-care and totally mediated the relationship between simple attention and selfcare and between working memory and self-care (comparative fit index range: .929-.968; root mean squared error of approximation range: .032-.052). Except for short-term memory, which had a direct effect on self-care maintenance, the other cognitive domains were unrelated to self-care.

Conclusions

Self-care confidence appears to be an important factor influencing heart failure self-care even in patients with impaired cognition. As few studies have successfully improved cognition, interventions addressing confidence should be considered as a way to improve self-care in this population.

\section{Keywords}

cognition, heart failure, mediation analysis, self-care, self-efficacy, treatment adherence 


\section{Disciplines}

Behavioral Medicine | Cardiology | Cardiovascular Diseases | Circulatory and Respiratory Physiology | Medical Humanities | Medicine and Health Sciences | Nursing | Preventive Medicine 
Self-care confidence may be more important than cognition to influence self-care behaviors in adults with heart failure: testing a mediation model

Ercole Vellone, PhD, RN

Postdoctoral Research Fellow in Nursing Science

Department of Biomedicine and Prevention

University of Rome "Tor Vergata", Rome, Italy

Luca Pancani, MSc

PhD student in Psychology

Department of Psychology

University of Milan - Bicocca, Milan, Italy

Andrea Greco, PhD

Postdoctoral Research Fellow in Psychology

Department of Psychology

University of Milan - Bicocca, Milan, Italy

Patrizia Steca, $\mathrm{PhD}$

Associate Professor

Department of Psychology

University of Milan - Bicocca, Milan, Italy

Barbara Riegel, PhD, RN, FAHA, FAAN

Edith Clemmer Steinbright Professor of Gerontology

University of Pennsylvania School of Nursing

Philadelphia, PA, USA

Corresponding author

Dr Ercole Vellone

Department of Biomedicine and Prevention

University of Rome Tor Vergata

Via Montpellier, 1, Rome 00133, Italy

E-mail: ercole.vellone@uniroma2.it

Tel.: +39 338 7491811; fax: +39 0672596961 .

Source of Funding: Supported by the National Heart, Lung, and Blood Institute (RO1

HL084394) and the VISN 4 Mental Illness Research, Education, and Clinical Center, Philadelphia Veterans Affairs Medical Center.

The authors gratefully acknowledge Stephen Moelter, $\mathrm{PhD}$, University of the Sciences, Philadelphia, PA, who reviewed a prior version of this manuscript. 


\begin{abstract}
Background. Cognitive impairment can reduce the self-care abilities of heart failure patients. Theory and preliminary evidence suggest that self-care confidence may mediate the relationship between cognition and self-care, but further study is needed to validate this finding.

Objectives. The aim of this study was to test the mediating role of self-care confidence between specific cognitive domains and heart failure self-care.

Design. Secondary analysis of data from a descriptive study.

Settings. Three out-patient sites in Pennsylvania and Delaware, USA.

Participants. A sample of 280 adults with chronic heart failure, 62 years old on average and mostly male $(64.3 \%)$.

Methods. Data on heart failure self-care and self-care confidence were collected with the Self-Care of Heart Failure Index 6.2. Data on cognition were collected by trained research assistants using a neuropsychological test battery measuring simple and complex attention, processing speed, working memory, and short-term memory. Sociodemographic data were collected by self-report. Clinical information was abstracted from the medical record. Mediation analysis was performed with structural equation modeling and indirect effects were evaluated with bootstrapping.
\end{abstract}

Results. Most participants had at least 1 impaired cognitive domain. In mediation models, self-care confidence consistently influenced self-care and totally mediated the relationship between simple attention and self-care and between working memory and self-care (comparative fit index ranges: .929-.968; root mean squared error of approximation ranges: .032-.052). Except for short-term memory, which had a direct effect on self-care maintenance, the other cognitive domains were unrelated to self-care.

Conclusions. Self-care confidence appears to be an important factor influencing heart failure selfcare even in patients with impaired cognition. As few studies have successfully improved cognition, interventions addressing confidence should be considered as a way to improve self-care in this population. 
Key words: Cognition; Heart failure; Mediation analysis; Self-Care; Self-efficacy; Treatment adherence

\section{Contribution of the paper}

What is already known about the topic?

- Cognitive impairment affects $25-50 \%$ of adults with heart failure;

- Cognitive impairment may reduce HF patient self-care but literature is inconsistent;

- Only one study reports that self-care confidence mediates between global cognition and heart failure self-care.

What this study adds?

- Self-care confidence totally mediates the relationship between simple attention and heart failure self-care;

- Self-care confidence totally mediates the relationship between working memory and heart failure self-care.

- Interventions addressing self-care confidence might be more effective than interventions based on cognitive training to improve self-care of heart failure patients 


\section{Introduction}

Heart failure is a pandemic syndrome affecting the $0.5-2 \%$ of the general population in western countries (Mozaffarian et al., 2015). Almost 6 million people in the US and 15 million people in Europe are affected by heart failure (McMurray et al., 2012; Mozaffarian et al., 2015). Because heart failure prevalence increases with age, it is predicted that by $2030,25 \%$ of the population will have heart failure (Heidenreich et al., 2013).

Heart failure patients experience poor outcomes such as decreased quality of life, repeated hospitalization, and high mortality rates (Falk et al., 2013; Lam and Smeltzer, 2012; Murthy and Lipman, 2011; Song et al., 2010). However, if patients perform adequate self-care they can improve these outcomes (Ditewig et al., 2010; Jones et al., 2012; Tung et al., 2013).

As defined by the situation-specific theory of heart failure self-care (Riegel and Dickson, 2008; Riegel et al., 2015), self-care is a process that involves self-care maintenance, symptom perception, and self-care management. The goal of self-care maintenance is to maintain physiologic stability through treatment adherence (e.g., medication adherence); symptom perception involves monitoring for changes (e.g., checking ankles for swelling); and self-care management, which includes the response to signs and symptoms of a heart failure exacerbation (e.g., recognize symptoms quickly). In the theory, self-care confidence, also referred to as self-efficacy in task-specific self-care behaviors, is said to mediate and/or moderate the self-care process (Riegel and Dickson, 2008; Riegel et al., 2015). That is, factors influencing self-care may do so through self-care confidence (mediation) or different levels of self-care confidence may change the manner in which these factors influence self-care (moderation) (Baron and Kenny, 1986).

An important factor thought to potentially influence self-care is cognition (Dickson et al., 2007). Cognitive impairment is found in $25-50 \%$ of adults with heart failure (Dodson et al., 2013; Gure et al., 2012; Pressler, 2008) but literature is inconsistent regarding the influence of cognitive impairment on heart failure self-care. In fact, some studies have shown that cognitive impairment affects self-care (Alosco et al., 2012; Harkness et al., 2013) while others have not (Cameron et al., 
2009). This inconsistency in the literature might be due to the effect of mediators or moderators (such as self-care confidence) that influence the relationship between cognition and self-care. In fact, in a recent study, self-care confidence totally mediated the relationship between cognition and self-care (Vellone et al., 2015), even though cognition was measured only with the Mini Mental State Examination that is useful for screening purposes but it is not advocated to evaluate specific cognitive domains in patients (Cameron et al., 2015). Knowing which specific domain of cognition influences self-care confidence and if self-care confidence mediates the relationship between these specific cognitive domains and self-care behaviors (self-care maintenance and management) would improve our understanding of potential ways to improve self-care. In fact, while it is well known that heart failure self-care can be improved via self-care confidence (Cox et al., 2013; Flynn et al., 2005; Pozehl et al., 2010; Smeulders et al., 2010), we do not have yet strong evidence showing that heart failure self-care can be improved via cognitive improvement (Pressler et al., 2011).

Therefore, the aim of this study was to test the mediating role of self-care confidence in the relationship between specific cognitive domains (simple and complex attention, processing speed, working memory, and short-term memory) and self-care maintenance and management as illustrated in Figure 1. As predicted by the situation-specific theory of heart failure self-care (Riegel and Dickson, 2008; Riegel et al., 2015) and prior work (Vellone et al., 2015), our hypothesis was that these cognitive domains would not have a direct effect on self-care behaviors but would affect self-care behaviors (self-care maintenance and management) only indirectly through self-care confidence.

\section{Methods}

\section{Design, sample and setting}

This was a secondary analysis of data from a descriptive cohort comparison study (Riegel et al., 2011). Methodology of the parent study has been published elsewhere (Riegel et al., 2011). Briefly, the aim of the parent study was to study the influence of excessive daytime sleepiness and cognition on heart failure self-care in a sample of 280 heart failure patients enrolled in 3 outpatient settings in 
Philadelphia, Pennsylvania and Newark, Delaware. Patients were enrolled if they had a diagnosis of heart failure, sufficient vision and hearing, with and without mild cognitive impairment (score in the range of $21-25$ on the Telephone Interview of Cognitive Status tool) (Brandt J, Folstein, 2003) and with ( $\geq 6$ on the Epworth Sleepiness Scale) (Johns, 1992) and without excessive daytime sleepiness (Johns, personal communication, 2007). Patients were excluded from the study if they lived in longterm care settings, worked at night, had renal failure requiring dialysis, were imminently terminal due to greatly advanced heart failure or another illness such as cancer, had a ventricular assist device, had an history of alcohol or drug abuse in the last year, or had major depression.

\section{Data Collection}

The study was approved by the Institutional Review Board of each center where patients were enrolled. Informed consent was formally obtained from each participant before data collection.

Self-care was measured using the Self-Care of Heart Failure Index version 6.2 (Riegel et al., 2009). The Self-Care of Heart Failure Index is a 22-item instrument that is widely used to measure self-care maintenance, management, and confidence; the concept of symptom perception is not measured separately in this version of the Self-Care of Heart Failure Index but the self-care maintenance scale measures both self-monitoring (e.g., checking weight daily) and treatment adherence (e.g., following a low salt diet, taking medications). The self-care management scale measures how quickly patients recognize and evaluate symptoms of a heart failure exacerbation (shortness of breath or ankle swelling), treatment for symptoms (e.g. reducing salt intake, consulting a provider) and treatment evaluation. The self-care confidence scale evaluates confidence in each phase of the self-care process (e.g. confidence in symptom management). Each Self-Care of Heart Failure Index scale (i.e., maintenance, management, confidence) yields a standardized score from 0 to 100 where higher scores mean better self-care. The Self-Care of Heart Failure Index has demonstrated validity and reliability (Barbaranelli et al., 2014).

Cognition was measured using a neuropsychological test battery measuring those domains known to be impaired in many adults with heart failure: simple and complex attention, processing 
speed, working memory, and short-term memory. The battery included: Psychomotor Vigilance Task (Dinges D, Kribbs N, Bates B, 1993), which measures simple attention, with a higher number of lapses in attention indicating worse cognition; the Trail Making Test B (Reitan, 1992), which assesses complex attention, with higher score indicating worse cognition; the Digit Symbol Substitution Task (The Psychological Corporation, 2002), which evaluates processing speed, with higher score indicating better cognition; the Probed Recall Memory Task (Lezak M, Howieson D, 2004), which evaluates working memory, with higher score meaning better cognition; and the Letter Number Sequencing test (The Psychological Corporation, 2002), which measures short-term memory, with higher score meaning better cognition. Each test yields a continuous score that can be also dichotomized according to the cut-offs reported in the literature and age-specific norms (The Psychological Corporation, 2002); the dichotomizations were used to compute a summary of the number of tests on which cognition was impaired. Because the cut-points are based on age-specific norms, test results are already adjusted for age. That score summarizing the number of abnormal tests ranged from $0-5$, with higher scores indicating worse cognition (Riegel et al., 2011).

Sociodemographic characteristics were self-reported. Most clinical information (e.g., illness duration, comorbidity, heart failure type and duration, left ventricular ejection fraction) was gathered from the medical record. Comorbidity was measured using the Charlson Comorbidity Index (Charlson et al., 1987); higher scores indicate higher comorbidity burden. A structured interview was used to gather information on symptom burden, which was used by a cardiologist to score New York Heart Association functional class (Kubo et al., 2004). Most of the data were collected during home visits by research assistants who were registered nurses or psychology master's students. Each of the three enrolling institutions hired separate research staff but all staff were trained in full-day training sessions conducted by the Principal Investigator, the Project Manager, and Co-Investigators. Training involved didactic content, practice sessions, and role playing of testing scenarios. Thereafter, staff met weekly or biweekly with the Project Manager to discuss issues and to assure consistency in data collection. 


\section{Data Analysis}

This secondary analysis was carried out in four steps. First, descriptive statistics were used to describe sociodemographic and clinical variables, Self-Care of Heart Failure Index scale scores (self-care maintenance, management and confidence), and neuropsychological test scores. Second, in order to detect possible associations that should be taken into account in the third step of the analysis, correlations were computed between Self-Care of Heart Failure Index scales and sociodemographic and clinical variables (i.e., age, gender, education, race, New York Heart Association class, and comorbidity). In particular, correlation coefficients higher than $|.29|$, the cutoff for weak correlation, were considered as a sufficient reason to adjust the following analysis for these effects. Third, structural equation modeling was used to test the mediating role of self-care confidence between cognition and self-care behaviors (self-care maintenance and management). In order to reduce the number of estimated parameters and to run the most reliable models compared to the number of observations, a single-indicator latent variable was used to compute self-care maintenance, management and confidence scores (Bollen, 1989). Maximum likelihood was used as the estimation method.

In the third step of the analysis, six models were tested, one using the summary cognition score and one for each of the five cognitive domains (i.e., simple attention, complex attention, processing speed, working memory, and short-term memory). In each model, self-care maintenance and self-care management were regressed on self-care confidence, the mediator in our analysis, and self-care confidence was regressed on the summary cognitive score or on one of the five cognition domains investigated. As specified in the situation-specific theory of heart failure self-care (Riegel et al., 2015), self-care management was regressed also on self-care maintenance because mastery of self-care maintenance is thought to precede mastery of self-care management. Moreover, self-care maintenance and management were regressed on the summary cognition score and on each specific cognition domain score to estimate the direct effects of cognition on self-care behaviors along with 
the indirect effects via self-care confidence.

In order to account for other variables known to influence cognition and self-care (Cocchieri et al., 2015), the summary cognition score and the specific cognitive domain scores were regressed on all the sociodemographic (i.e., age, gender, education, and ethnicity) and clinical (i.e., New York Heart Association functional class and comorbidity) variables. The only exception to this analysis strategy was in the analysis of the summary cognition score, which was not regressed on age since this score had already been adjusted for age when it was computed. Finally, self-care maintenance, management and confidence scores were regressed on illness duration (expressed in months) because it is known that illness duration affects self-care (Cocchieri et al., 2015). Further paths between sociodemographic or clinical variables and self-care maintenance, management and confidence scores were included in the models according to the correlation analysis conducted in the first step. The fit of the various models was evaluated using the indices reported in Table 3 (Bollen, 1989; Brown, 2006; Kline, 2011).

In the fourth step of our analysis the indirect effects of the summary cognition score and the specific cognitive domain scores on self-care maintenance and management through self-care confidence were estimated, as specified in Figure 1. Indirect effects and their significance were assessed through bootstrapping method (MacKinnon, 2008; MacKinnon et al., 2004) using 5,000 replications of the original sample and considering a $90 \%$ confidence interval. Bootstrapping is necessary to estimate significance of indirect effects because the distribution of these product terms is often skewed. Data were analyzed using SPSS version 20 (SPSS, Chicago, IL, USA) and Mplus version 6.11 (Muthén and Muthén, 2015).

\section{Results}

\section{Descriptive statistics and correlation analysis}

A total of 280 individuals with an age range of 24 to 89 years (Mean=62.0, $\mathrm{SD}=12.5$ ) were enrolled in the study; complete descriptive statistics are summarized in Table 1 . The majority of participants were males (64.3\%) with at least a high school degree $(90.3 \%)$, either White $(62.5 \%)$ or 
Black (34.3\%); only 3.2\% belonged to other racial or ethnic groups. Therefore, this latter category was coded as missing because its under-representation would have compromised the parameters estimation regarding this variable in the models. The average Charlson Comorbidity Index score was $2.8(\mathrm{SD}=1.7)$, indicating a moderate level of comorbidity, and the majority of patients were assessed to have significant functional limitation with 58.8\% in New York Heart Association class III. The average illness duration was about 6 years but it ranged from a few months to more than 25 years.

Cognitive performance was poor on the Trail Making Test B (Reitan, 1992), with $61.1 \%$ of patients demonstrating problems with complex attention. The best performance was seen on the Letter Number Sequencing Test (The Psychological Corporation, 2002), with only $16.1 \%$ of patients demonstrating poor short-term memory. The average summary cognition impairment score was $1.7(\mathrm{SD}=1.0)$ and the vast majority of patients had at least 1 test in which they demonstrated impairment (93.2\%).

Correlation analysis showed that none of the sociodemographic and clinical variables were significantly correlated with self-care maintenance, management or confidence scales (Table 2), thus these scale scores were not adjusted for these variables in the mediation analysis.

\section{Mediation analysis}

Mediation analysis, performed with a series of structural equation models, showed that selfcare confidence totally mediated the relationship between simple attention and self-care behaviors (both self-care maintenance and management) and between working memory and self-care behaviors (Figure 2). Also, as predicted theoretically, self-care maintenance was also a mediator between self-care confidence and self-care management. The summary cognition score, processing speed, complex attention, and short-term memory were neither mediated by self-care confidence nor had a significant relationship with self-care behaviors (data not shown), with the only exception being short-term memory, which had a significant direct effect on self-care maintenance $(\beta=.16, p<$ 
.05 ). All the models tested yielded acceptable fit indices (Table 3), except for a significant but negligible $\chi^{2}$ value for the processing speed model.

Table 4 shows the indirect effects tested for each model. Simple attention and working memory were the only cognitive domains that indirectly and significantly influenced self-care behaviors (self-care maintenance and management) through self-care confidence. Specifically, working memory influenced self-care confidence first, and then self-care maintenance; simple attention influenced self-care confidence first, then self-care maintenance and lastly self-care management.

The tested models (Figure 2) also showed significant relationships with the other variables. Concerning sociodemographic and clinical variables, three results are worth mentioning. First, age was found to significantly affect all the cognitive domain scores (regression coefficients ranged from -.17 to -.42), indicating that the higher the age the worse the cognitive performance. Second, New York Heart Association functional class had no significant effects, either on the summary cognition score, or on the specific cognitive domains $(p>.05)$. Third, illness duration positively and significantly influenced self-care confidence (regression coefficients ranged from 0.15 to 0.16 ) and management (from .20 to .21 ) in all tested models, but not self-care maintenance $(p>.05)$.

\section{Discussion}

The aim of this study was to analyse the mediating role of self-care confidence in the relationship between cognition and self-care behaviors. Results illustrate that self-care confidence totally mediated the relationship between simple attention and self-care behaviors and between working memory and self-care behaviors. As the second study of this relationship, these results confirm the important role of self-care confidence in mediating the heart failure self-care process.

In the current study a battery of neuropsychological tests was used to evaluate heart failure patients' abilities in multiple cognitive domains, lending a more precise understanding of the mediating role of self-care confidence than that achieved in the prior study by Vellone et al (2015). In that study, the investigators used the Mini Mental State Examination, a general measure of 
cognitive performance with well-known limitations including a ceiling effect in the heart failure population (Cameron et al., 2015); thus heart failure patients may achieve a high score on the Mini Mental State Examination even though they have mild cognitive impairment.

In Vellone et al. (2015) study the investigators found that self-care confidence totally mediated the relationship between global cognition and self-care behaviors. In the present study self-care confidence totally mediated only the relationship between measures of simple attention (Psychomotor Vigilance Task) and working memory (Probed Recall Memory Task) and self-care behaviors. The summary cognition score, complex attention, and processing speed were not significantly related to self-care confidence, maintenance or management in our models, and shortterm memory had only a direct effect on self-care maintenance. The analysis of the present study suggests that confidence is only operant in those heart failure patients with problems in the areas of attention and working memory. In these patients, a lack of confidence performing self-care may have led to reduced ratings of self-care. These results are similar to those of Kim et al. (2015) who showed that only memory, and not global cognition, predicted self-care maintenance and self-care confidence.

In the models tested in this study, self-care confidence always influenced self-care behaviors, which reinforces the situation-specific theory of heart failure self-care which specifies this relationship. Except for short-term memory, which had a direct effect on self-care maintenance, no specific cognitive domains directly affected self-care behaviors of maintenance and management. These results suggest that impaired cognition negatively influences self-care behaviors indirectly through self-care confidence. Although this finding was observed only for simple attention and working memory, it highlights the importance of self-care confidence, which seems to have a greater direct impact than cognition on performance of self-care behaviors.

Complex attention and processing speed, elements of executive functions, had no direct effect on self-care behaviors. Also, complex attention and processing speed were not mediated by self-care confidence in our models. Executive function is known to influence decision-making skills 
(Gaviria et al., 2011), which could be important in the case of heart failure decompensation when it is essential to act to relieve symptoms (e.g., call the provider). The results of our study support prior theoretical and empirical works illustrating that decision-making regarding self-care is not necessarily logical but is more influenced by a naturalistic decision-making process where prior experiences, values, culture, environment, social support, knowledge and real-world context influence decision-making (Riegel et al., 2015). Also, as proposed in the middle range theory of self-care in chronic illness (Riegel et al., 2012), sufficient self-care may or may not be associated with good decision-making skills. In the study conducted by Dickson et al. (2011), poorer cognitive function was associated with better self-care, which the authors explained as probably due to social support.

These results have important clinical implications. While several authors recommend routine assessment of cognition in heart failure patient (Alosco et al., 2012, Hanon et al., 2014), our results suggest that routinely assessing self-care confidence may be important as well if we want to improve self-care behaviors. In fact, prior studies (Davis et al., 2012; Flynn et al., 2005; Pozehl et al., 2010; Smeulders et al., 2010) have shown that interventions addressing self-care confidence might be more effective than interventions based on cognitive training to improve self-care behaviors of heart failure patients. Also, in a recent systematic review (Clark et al., 2016), self-care confidence and not cognition was identified as one the mechanisms that was important for success in heart failure programs.

This study has several limitations. First, this was a secondary analysis of data from a study aimed at determining if self-care differed in adults with heart failure on the basis of excessive daytime sleepiness and if cognition influenced the relationship. Consequently, no patients with severe cognitive impairment were enrolled in the study. Second, the analysis was conducted on cross-sectional data and consequently we cannot infer causal relationships among the variables. Third, we measured self-care with a self-report instrument that might affect the precision of measurement. However, Self-Care of Heart Failure Index scores have been shown to distinguish 
patients educated in self-care from those who are not $(\mathrm{p}<0.001)$ (Vellone et al., 2013) and to be significantly correlated with urinary sodium excretion (Song et al., 2010) and lower levels of serum biomarkers of myocardial stress and systemic inflammation (Lee et al., 2011). Fourth, our sample was younger and better educated than the general heart failure population. Fifth, self-care levels were slightly higher than those found in the general heart failure population (Jaarsma et al., 2013). However, our analysis controlled for this variable.

Recommendations for future research include the need to test the mediation model with longitudinal data and to include other cognitive domains such as language and visuospatial ability. These two cognitive domains may not be compromised by heart failure but few studies have been conducted to examine them (Leto and Feola, 2014). Since self-care confidence seems to be a powerful mediator between predictors of self-care and self-care itself, as other studies have shown (Cené et al., 2013; Sayler et al., 2012), future studies should test the mediating role of self-care confidence in the relationship between other factors (e.g., sleep, knowledge on heart failure, depression and anxiety) and self-care in heart failure patients. If future studies confirm that self-care confidence is a powerful influence on self-care behaviors, interventions aimed at improving selfcare confidence should be tested. 


\section{References}

Alosco, M.L., Spitznagel, M.B., Cohen, R., Sweet, L.H., Colbert, L.H., Josephson, R., Waechter, D., Hughes, J., Rosneck, J., Gunstad, J., 2012. Cognitive impairment is independently associated with reduced instrumental activities of daily living in persons with heart failure. $\mathrm{J}$. Cardiovasc. Nurs. 27, 44-50. doi:10.1097/JCN.0b013e318216a6cd

Barbaranelli, C., Lee, C.S., Vellone, E., Riegel, B., 2014. Dimensionality and reliability of the selfcare of heart failure index scales: further evidence from confirmatory factor analysis. Res. Nurs. Heal. 37, 524-537. doi:10.1002/nur.21623

Baron, R.M., Kenny, D.A., 1986. The moderator-mediatorvariable distinction in social psychological research: conceptual, strategic and statistical considerations. J. Pers. Soc. Psychol. 51, 1173-1182.

Bollen, K.A., 1989. Structural equations with latent variables. Wiley, New York.

Brandt J, Folstein, M.F., 2003. Telephone interview for cognitive status. Psychological Assessment Resources, Lutz, FL.

Brown, T.A., 2006. Confirmatory factor analysis for applied research. Guilford Press, New York.

Cameron, J., Kure, C.E., Pressler, S.J., Ski, C.F., Clark, A.M., Thompson, D.R., 2015. Diagnostic Accuracy of Cognitive Screening Instruments in Heart Failure: A Systematic Review. J. Cardiovasc. Nurs. doi:10.1097/JCN.0000000000000285

Cameron, J., Worrall-Carter, L., Riegel, B., Lo, S.K., Stewart, S., 2009. Testing a model of patient characteristics, psychologic status, and cognitive function as predictors of self-care in persons with chronic heart failure. Hear. Lung 38, 410-418. doi:10.1016/j.hrtlng.2008.11.004

Cené, C.W., Haymore, L.B., Dolan-Soto, D., Lin, F.-C., Pignone, M., Dewalt, D.A., Wu, J.-R., Jones, C.D., Corbie-Smith, G., 2013. Self-care confidence mediates the relationship between perceived social support and self-care maintenance in adults with heart failure. J. Card. Fail. 19, 202-10. doi:10.1016/j.cardfail.2013.01.009

Charlson, M., Pompei, P., Ales, K., MacKenzie, C., 1987. A new method of classifying prognostic 
comorbidity in longitudinal studies: Development and validation. J. Chronic Dis. 40, 373-383.

Clark, A.M., Wiens, K., Banner, D., Kryworuchko, J., Thirsk, L., McLean, L., Currie, K., 2016. A systematic review of the main mechanisms of heart failure disease management interventions. Heart heartjnl-2015-308551. doi:10.1136/heartjnl-2015-308551

Cocchieri, A., Riegel, B., D’Agostino, F., Rocco, G., Fida, R., Alvaro, R., Vellone, E., 2015. Describing self-care in Italian adults with heart failure and identifying determinants of poor self-care. Eur. J. Cardiovasc. Nurs. 14, 126-136. doi:10.1177/1474515113518443

Cox, K.L., Flicker, L., Almeida, O.P., Xiao, J., Greenop, K.R., Hendriks, J., Phillips, M., Lautenschlager, N.T., 2013. The FABS trial: a randomised control trial of the effects of a 6month physical activity intervention on adherence and long-term physical activity and selfefficacy in older adults with memory complaints. Prev. Med. (Baltim). 57, 824-830. doi:10.1016/j.ypmed.2013.09.010

Davis, K.K., Mintzer, M., Dennison Himmelfarb, C.R., Hayat, M.J., Rotman, S., Allen, J., 2012. Targeted intervention improves knowledge but not self-care or readmissions in heart failure patients with mild cognitive impairment. Eur. J. Heart Fail. 14, 1041-1049. doi:10.1093/eurjhf/hfs096

Dickson, V. V, Lee, C.S., Riegel, B., 2011. How Do Cognitive Function and Knowledge Affect Heart Failure Self-Care? J. Mix. Methods Res. 5, 167-189. doi:10.1177/1558689811402355

Dickson, V. V, Tkacs, N., Riegel, B.A., 2007. Cognitive influences on self-care decision making in persons with heart failure. Am. Heart J. 154, 424-431. doi:10.1016/j.ohi.2007.04.058

Dinges D, Kribbs N, Bates B, C.M., 1993. A very brief probed recall memory task: sensitivity to sleep loss. 1993;22:330. Sleep Res 22, 330.

Ditewig, J.B., Blok, H., Havers, J., van Veenendaal, H., 2010. Effectiveness of self-management interventions on mortality, hospital readmissions, chronic heart failure hospitalization rate and quality of life in patients with chronic heart failure: a systematic review. Patient Educ. Couns. 78, 297-315. doi:10.1016/j.pec.2010.01.016 
Dodson, J.A., Truong, T.T., Towle, V.R., Kerins, G., Chaudhry, S.I., 2013. Cognitive impairment in older adults with heart failure: prevalence, documentation, and impact on outcomes. Am. J. Med. 126, 120-126. doi:10.1016/j.amjmed.2012.05.029

Falk, H., Ekman, I., Anderson, R., Fu, M., Granger, B., 2013. Older Patients' Experiences of Heart Failure-An Integrative Literature Review. J. Nurs. Scholarsh. doi:10.1111/jnu.12025

Flynn, K.J., Powell, L.H., Mendes de Leon, C.F., Munoz, R., Eaton, C.B., Downs, D.L., Silver, M.A., Calvin, J.E., 2005. Increasing self-management skills in heart failure patients: a pilot study. Congest. Hear. Fail. 11, 297-302.

Gaviria, M., Pliskin, N., Kney, A., 2011. Cognitive impairment in patients with advanced heart failure and its implications on decision-making capacity. Congest. Hear. Fail. 17, 175-179. doi:10.1111/j.1751-7133.2011.00242.x

Gure, T.R., Blaum, C.S., Giordani, B., Koelling, T.M., Galecki, A., Pressler, S.J., Hummel, S.L., Langa, K.M., 2012. Prevalence of cognitive impairment in older adults with heart failure. J. Am. Geriatr. Soc. 60, 1724-1729. doi:10.1111/j.1532-5415.2012.04097.x

Harkness, K., Heckman, G.A., Akhtar-Danesh, N., Demers, C., Gunn, E., McKelvie, R.S., 2013. Cognitive function and self-care management in older patients with heart failure. Eur. J. Cardiovasc. Nurs. doi:10.1177/1474515113492603

Heidenreich, P.A., Albert, N.M., Allen, L.A., Bluemke, D.A., Butler, J., Fonarow, G.C., Ikonomidis, J.S., Khavjou, O., Konstam, M.A., Maddox, T.M., Nichol, G., Pham, M., Pina, I.L., Trogdon, J.G., 2013. Forecasting the impact of heart failure in the United States: a policy statement from the American Heart Association. Circ Hear. Fail 6, 606-619. doi:10.1161/HHF.0b013e318291329aHHF.0b013e318291329a [pii]

Jaarsma, T., Strömberg, A., Ben Gal, T., Cameron J, Driscoll, A., Duengen, H.D., Huang, T., Huyen, N.N., Inkrot, S., Kato, N., Köberich, S., Lupón, J., Moser, D.K., Pulignano, G., Rabelo, E.R., Suwanno, J., Thompson, D.R., Vellone, E., Alvaro, R., Yu, D., Riegel, B., 2013. Comparison of self-care behaviours of heart failure patients in 15 countries worldwide. Patient 
Educ. Couns. 92, 114-120. doi:10.1016/j.pec.2013.02.017

Johns, M.W., 1992. Reliability and factor analysis of the Epworth Sleepiness Scale. Sleep 15, 37681.

Jones, C.D., Holmes, G.M., Dewalt, D.A., Erman, B., Broucksou, K., Hawk, V., Cene, C.W., Wu, J.R., Pignone, M., 2012. Is adherence to weight monitoring or weight-based diuretic selfadjustment associated with fewer heart failure-related emergency department visits or hospitalizations? J. Card. Fail. 18, 576-584. doi:10.1016/j.cardfail.2012.05.004

Kim, J.S., Hwang, S.Y., Shim, J.L., Jeong, M.H., 2015. Cognitive Function and Self-Care in Patients with Chronic Heart Failure. Korean Circ J 45, 310-316. doi:10.4070/kcj.2015.45.4.310

Kline, R.B., 2011. Principles and practice of structural equation modeling, 3th ed. The Guilford Press, New York.

Kubo, S., Schulman, S., Starling, R., Jessup, M., Wentworth, D., Burkhoff, D., 2004. Development and validation of a patient questionnaire to determine New York Heart Association Classification. J. Card. Fail. 10, 228-235.

Lam, C., Smeltzer, S.C., 2012. Patterns of Symptom Recognition, Interpretation, and Response in Heart Failure Patients: An Integrative Review. J. Cardiovasc. Nurs. 28, 348-359. doi:10.1097/JCN.0b013e3182531cf7

Lee, C.S., Moser, D.K., Lennie, T.A., Tkacs, N.C., Margulies, K.B., Riegel, B., 2011. Biomarkers of Myocardial Stress and Systemic Inflammation in Patients Who Engage in Heart Failure Self-care Management. J. Cardiovasc. Nurs. 26, 321-328. doi:10.1097/JCN.0b013e31820344be

Leto, L., Feola, M., 2014. Cognitive impairment in heart failure patients. J. Geriatr. Cardiol. 11, $316-328$.

Lezak M, Howieson D, L.D., 2004. Neuropsychological assessment, 4th ed. Oxford University Press, New York. 
MacKinnon, D.P., 2008. Introduction to statistical mediation analysis. Erlbaum, Mahwah, NJ.

MacKinnon, D.P., Lockwood, C.M., Williams, J., 2004. Confidence limits for the indirect effect:

Distribution of the product and resampling methods. Multivariate Behav. Res. 39.

McMurray, J.J., Adamopoulos, S., Anker, S.D., Auricchio, A., Bohm, M., Dickstein, K., Falk, V., Filippatos, G., Fonseca, C., Gomez-Sanchez, M.A., Jaarsma, T., Kober, L., Lip, G.Y., Maggioni, A.P., Parkhomenko, A., Pieske, B.M., Popescu, B.A., Ronnevik, P.K., Rutten, F.H., Schwitter, J., Seferovic, P., Stepinska, J., Trindade, P.T., Voors, A.A., Zannad, F., Zeiher, A., Task Force for the, D., Treatment of, A., Chronic Heart Failure of the European Society of, C., Bax, J.J., Baumgartner, H., Ceconi, C., Dean, V., Deaton, C., Fagard, R., Funck-Brentano, C., Hasdai, D., Hoes, A., Kirchhof, P., Knuuti, J., Kolh, P., McDonagh, T., Moulin, C., Popescu, B.A., Reiner, Z., Sechtem, U., Sirnes, P.A., Tendera, M., Torbicki, A., Vahanian, A., Windecker, S., McDonagh, T., Sechtem, U., Bonet, L.A., Avraamides, P., Ben Lamin, H.A., Brignole, M., Coca, A., Cowburn, P., Dargie, H., Elliott, P., Flachskampf, F.A., Guida, G.F., Hardman, S., Iung, B., Merkely, B., Mueller, C., Nanas, J.N., Nielsen, O.W., Orn, S., Parissis, J.T., Ponikowski, P., Guidelines, E.S.C.C. for P., 2012. ESC guidelines for the diagnosis and treatment of acute and chronic heart failure 2012: The Task Force for the Diagnosis and Treatment of Acute and Chronic Heart Failure 2012 of the European Society of Cardiology. Developed in collaboration with the Heart. Eur. J. Heart Fail. 14, 803-869. doi:10.1093/eurjhf/hfs105

Mozaffarian, D., Benjamin, E.J., Go, A.S., Arnett, D.K., Blaha, M.J., Cushman, M., de Ferranti, S., Despres, J.P., Fullerton, H.J., Howard, V.J., Huffman, M.D., Judd, S.E., Kissela, B.M., Lackland, D.T., Lichtman, J.H., Lisabeth, L.D., Liu, S., Mackey, R.H., Matchar, D.B., McGuire, D.K., Mohler 3rd, E.R., Moy, C.S., Muntner, P., Mussolino, M.E., Nasir, K., Neumar, R.W., Nichol, G., Palaniappan, L., Pandey, D.K., Reeves, M.J., Rodriguez, C.J., Sorlie, P.D., Stein, J., Towfighi, A., Turan, T.N., Virani, S.S., Willey, J.Z., Woo, D., Yeh, R.W., Turner, M.B., 2015. Heart disease and stroke statistics--2015 update: a report from the 
American Heart Association. Circulation 131, e29-322.

doi:10.1161/CIR.0000000000000152CIR.0000000000000152 [pii]

Murthy, S., Lipman, H.I., 2011. Management of end-stage heart failure. Prim. Care 38, 265-276. doi:10.1016/j.pop.2011.03.007

Muthén, L.K., Muthén, B.O., 2015. Mplus user's guide, 5th Ed. ed. Muthén \& Muthén, Los Angeles, CA.

Pozehl, B., Duncan, K., Hertzog, M., Norman, J.F., 2010. Heart Failure Exercise And Training Camp: effects of a multicomponent exercise training intervention in patients with heart failure. Hear. Lung 39, S1-13. doi:10.1016/j.hrtlng.2010.04.008

Pressler, S.J., 2008. Cognitive functioning and chronic heart failure: a review of the literature (2002-July 2007). J. Cardiovasc. Nurs. 23, 239-249. doi:10.1097/01.JCN.0000305096.09710.ec

Pressler, S.J., Therrien, B., Riley, P.L., Chou, C.C., Ronis, D.L., Koelling, T.M., Smith, D.G., Sullivan, B.J., Frankini, A.M., Giordani, B., 2011. Nurse-Enhanced Memory Intervention in Heart Failure: the MEMOIR study. J. Card. Fail. 17, 832-843. doi:10.1016/j.cardfail.2011.06.650

Reitan, R.., 1992. Trail making test. Reitan Neuropsychological Laboratory, Tucson, AZ.

Riegel, B., Dickson, V. V, 2008. A situation-specific theory of heart failure self-care. J. Cardiovasc. Nurs. 23, 190-196. doi:10.1097/01.JCN.0000305091.35259.85

Riegel, B., Dickson, V. V, Faulkner, K.M., 2015. The Situation-Specific Theory of Heart Failure Self-Care: Revised and Updated. J. Cardiovasc. Nurs. doi:10.1097/JCN.0000000000000244 Riegel, B., Jaarsma, T., Stromberg, A., 2012. A middle-range theory of self-care of chronic illness. ANS Adv. Nurs. Sci. 35, 194-204. doi:10.1097/ANS.0b013e318261b1ba

Riegel, B., Lee, C.S., Dickson, V. V, Carlson, B., 2009. An update on the self-care of heart failure index. J. Cardiovasc. Nurs. 24, 485-497. doi:10.1097/JCN.0b013e3181b4baa0

Riegel, B., Moelter, S.T., Ratcliffe, S.J., Pressler, S.J., De Geest, S., Potashnik, S., Fleck, D., Sha, 
D., Sayers, S.L., Weintraub, W.S., Weaver, T.E., Goldberg, L.R., 2011. Excessive daytime sleepiness is associated with poor medication adherence in adults with heart failure. J. Card. Fail. 17, 340-348. doi:10.1016/j.cardfail.2010.11.002

Sayler, J., Schubert, C.M., Chiaranai, C., 2012. Supportive relationships, self-care confidence, and heart failure self-care. J. Cardiovasc. Nurs. 27, 384-393.

Smeulders, E.S., van Haastregt, J.C., Ambergen, T., Uszko-Lencer, N.H., Janssen-Boyne, J.J., Gorgels, A.P., Stoffers, H.E., Lodewijks-van der Bolt, C.L., van Eijk, J.T., Kempen, G.I., 2010. Nurse-led self-management group programme for patients with congestive heart failure: randomized controlled trial. J. Adv. Nurs. 66, 1487-1499. doi:10.1111/j.13652648.2010.05318.x

Song, E.K., Moser, D.K., Rayens, M.K., Lennie, T.A., 2010. Symptom clusters predict event-free survival in patients with heart failure. J. Cardiovasc. Nurs. 25, 284-291. doi:10.1097/JCN.0b013e3181cfbcbb

The Psychological Corporation, 2002. WAIS-III technical manual. Harcourt Assessment Co., San Antonio, TX.

Tung, H.H., Lin, C.Y., Chen, K.Y., Chang, C.J., Lin, Y.P., Chou, C.H., 2013. Self-management intervention to improve self-care and quality of life in heart failure patients. Congest. Hear. Fail. 19, E9-E16. doi:10.1111/chf.12014

Vellone, E., Fida, R., D’Agostino, F., Mottola, A., Juarez-Vela, R., Alvaro, R., Riegel, B., 2015. Self-care confidence may be the key: A cross-sectional study on the association between cognition and self-care behaviors in adults with heart failure. Int. J. Nurs. Stud. 52, 1705-13. doi:http://dx.doi.org/10.1016/j.ijnurstu.2015.06.013

Vellone, E., Riegel, B., Cocchieri, A., Barbaranelli, C., D’Agostino, F., Antonetti, G., Glaser, D., Alvaro, R., 2013. Psychometric testing of the self-care of heart failure index version 6.2. Res. Nurs. Heal. 36, 500-511. 


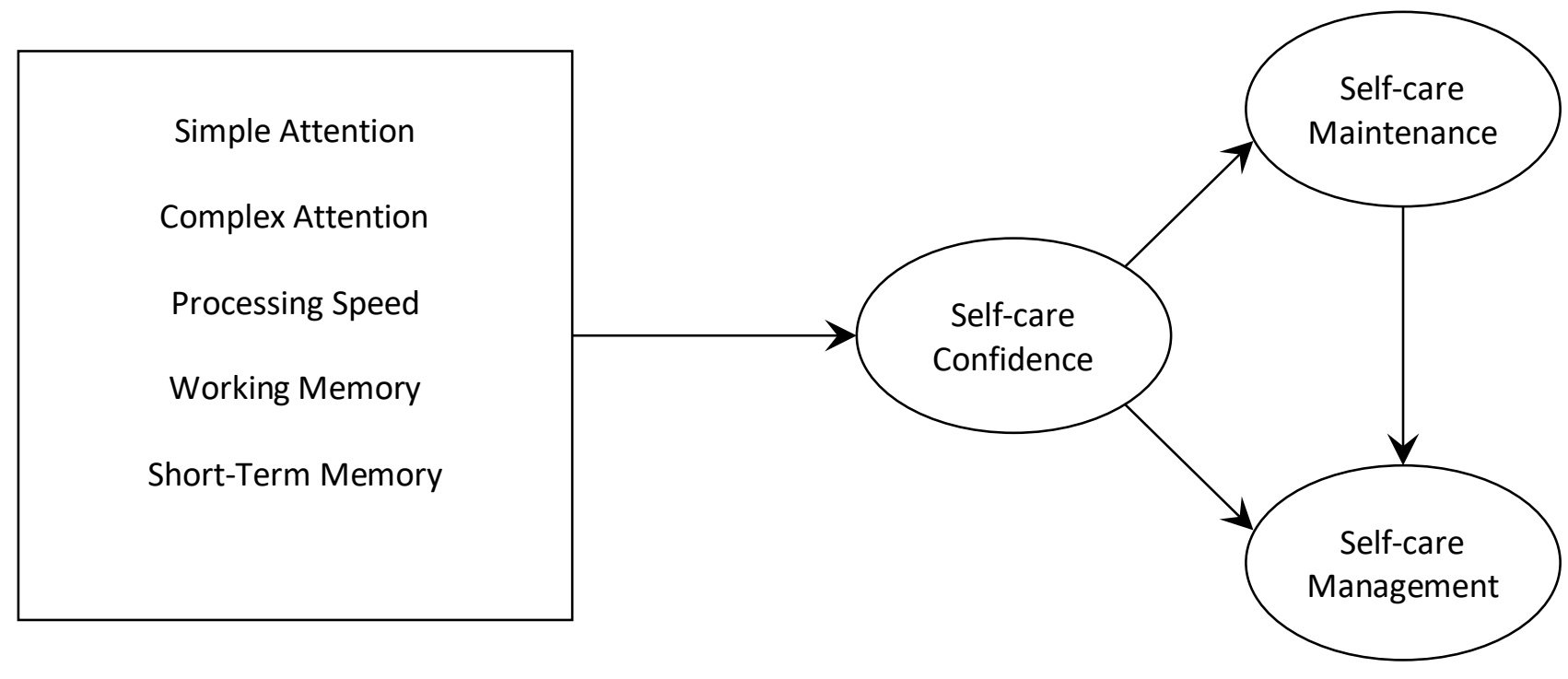

Figure 1. The conceptual model guiding the study. 
Table 1. Sample characteristics $(\mathrm{n}=280)$ : descriptive statistics of sociodemographic and clinical variables, self-care factors, and cognitive scores.

\begin{tabular}{|c|c|c|c|c|}
\hline \multirow{2}{*}{$\begin{array}{l}\text { Variable (dummy code) } \\
\text { Age }\end{array}$} & \multicolumn{2}{|c|}{ Mean (SD) } & \multicolumn{2}{|c|}{ Frequency $(\%)$} \\
\hline & 62.0 & $(12.5)$ & & \\
\hline \multicolumn{5}{|l|}{ Gender } \\
\hline Female (1) & & & 100 & $(35.7)$ \\
\hline Male (2) & & & 180 & $(64.3)$ \\
\hline \multicolumn{5}{|l|}{ Education } \\
\hline Less than high school degree (1) & & & 27 & $(9.6)$ \\
\hline High school degree (2) & & & 102 & $(36.4)$ \\
\hline More than high school degree (3) & & & 151 & $(53.9)$ \\
\hline \multicolumn{5}{|l|}{ Ethnic group } \\
\hline Black (1) & & & 96 & $(34.3)$ \\
\hline White (2) & & & 175 & $(62.5)$ \\
\hline Other (missing value) & & & 9 & $(3.2)$ \\
\hline \multicolumn{5}{|l|}{ NYHA functional class } \\
\hline Class I (1) & & & 12 & $(4.3)$ \\
\hline Class II (2) & & & 54 & $(19.3)$ \\
\hline Class III (3) & & & 164 & $(58.6)$ \\
\hline Class IV (4) & & & 50 & $(17.9)$ \\
\hline Charlson Comorbidity Index) & 2.8 & $(1.7)$ & & \\
\hline Illness duration (in months) & 73.4 & $(65.9)$ & & \\
\hline Self-care Maintenance & 66.8 & $(11.9)$ & & \\
\hline Self-care Management & 67.4 & $(18.7)$ & & \\
\hline Self-care Confidence & 75.8 & $(14.1)$ & & \\
\hline Summary Cognitive Score & 1.7 & $(1.0)$ & & \\
\hline Psychomotor Vigilance Task & 5.0 & $(3.5)$ & & \\
\hline Impaired patients & & & 109 & $(38.9)$ \\
\hline Trail Making Test B & 111.2 & $(59.1)$ & & \\
\hline Impaired patients & & & 171 & $(61.1)$ \\
\hline Digit Symbol Substitution Test & 53.4 & $(17.5)$ & & \\
\hline Impaired patients & & & 59 & $(21.1)$ \\
\hline Probed Recall Memory Task & 2.0 & $(1.2)$ & & \\
\hline Impaired patients & & & 95 & (33.9) \\
\hline Letter Number Sequencing Test & 8.7 & $(3.5)$ & & \\
\hline Impaired patients & & & 45 & $(16.1)$ \\
\hline
\end{tabular}


Table 2. Correlation analysis

\begin{tabular}{llll}
\hline & $\begin{array}{l}\text { Self-care } \\
\text { maintenance }\end{array}$ & $\begin{array}{l}\text { Self-care } \\
\text { management }\end{array}$ & $\begin{array}{l}\text { Self-care } \\
\text { confidence }\end{array}$ \\
\hline Age & .071 & -.095 & .035 \\
Gender & -.076 & -.070 & .001 \\
Education & .097 & .089 & .022 \\
Ethnicity & .008 & -.160 & -.011 \\
NYHA functional class & -.073 & .014 & -.055 \\
Charlson Comorbidity Index & .096 & .095 & -.007 \\
\hline
\end{tabular}

Note. Pearson's $r$ was used for continuous variables (i.e., age and comorbidity), Spearman's $\rho$ for categorical variables (i.e., gender, education, ethnicity, New York Heart Association class). No coefficient was statistically significant. 


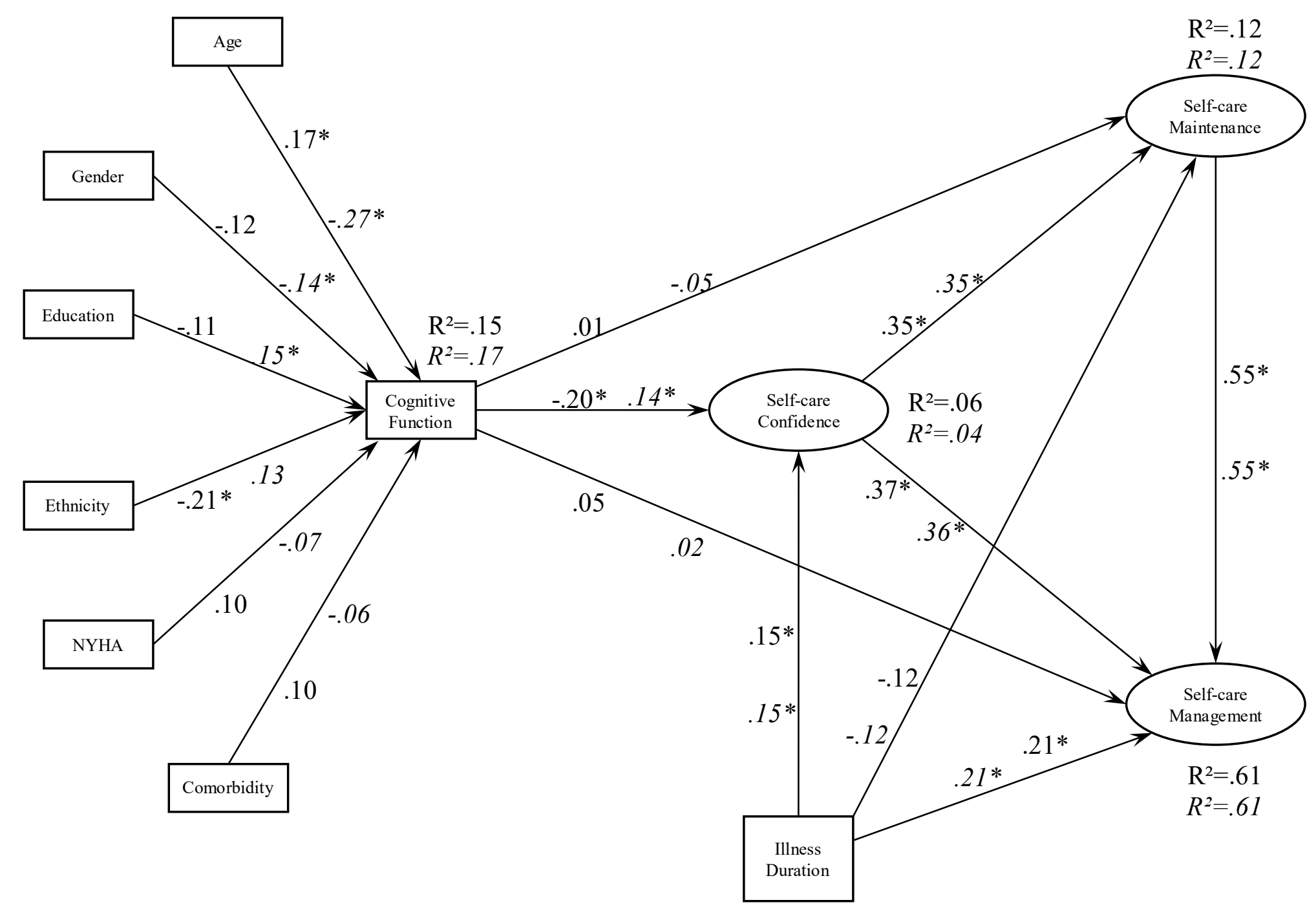

Figure 2. The results of the simple attention and working memory models. Standardized regression coefficients and R-square values for the simple attention model are in Roman text, for the working memory model are in Italics; * $p<.05$. 
Table 3. The fit indices for the structural equation models relative to the summary cognitive score and each cognitive domain.

\begin{tabular}{lllllll}
\hline & $\chi^{2}$ & df & $p$ value & CFI & RMSEA & Cfit \\
\hline Summary cognitive score model & 23.53 & 16 & .100 & .929 & .043 & .582 \\
Processing speed model & 31.88 & 19 & .032 & .942 & .052 & .425 \\
Simple attention model & 25.10 & 19 & .157 & .941 & .036 & .719 \\
Complex attention model & 27.02 & 19 & .104 & .954 & .041 & .637 \\
Working memory model & 26.11 & 19 & .127 & .936 & .039 & .676 \\
Short-term memory model & 23.85 & 19 & .202 & .968 & .032 & .769 \\
\hline
\end{tabular}

Note. CFI = Comparative Fit Index; RMSEA= Root mean squared error of approximation;

Cfit=closeness of fit of RMSEA. A good model yields a non-significant $\chi^{2}$ and Cfit ( $p>.05$ ), a CFI higher than .95 or at least .90 and the RMSEA lower than .05 or at least .08 . 
Table 4 - Test of the indirect effects estimated for each model: normal theory test and bootstrapped conditional indirect effects.

\begin{tabular}{|c|c|c|c|c|c|}
\hline \multirow[b]{2}{*}{ Indirect Effect } & \multirow[b]{2}{*}{ Cognitive domain } & \multicolumn{4}{|c|}{$\begin{array}{c}\text { Bootstrapping } \\
90 \% \text { C.I. }\end{array}$} \\
\hline & & Estimate & Lower & Upper & Sig. \\
\hline \multirow{6}{*}{$\begin{array}{c}\text { Self-care Confidence --> Self-care } \\
\text { Maintenance --> Self-care } \\
\text { Management }\end{array}$} & Summary cognitive score & .184 & .091 & .277 & $*$ \\
\hline & Processing speed & .186 & .095 & .276 & $*$ \\
\hline & Simple attention & .188 & .093 & .284 & $*$ \\
\hline & Complex attention & .186 & .095 & .277 & $*$ \\
\hline & Working memory & .191 & .097 & .286 & $*$ \\
\hline & Short-term memory & .192 & .097 & .287 & $*$ \\
\hline \multirow{6}{*}{$\begin{array}{c}\text { Specific Cognitive Function --> Self- } \\
\text { care Confidence --> Self-care } \\
\text { Management }\end{array}$} & Summary cognitive score & -.018 & -.068 & .033 & ns \\
\hline & Processing speed & .028 & -.021 & .078 & ns \\
\hline & Simple attention & -.073 & -.138 & -.008 & $*$ \\
\hline & Complex attention & -.020 & -.071 & .030 & ns \\
\hline & Working memory & .050 & -.003 & .104 & ns \\
\hline & Short-term memory & .001 & -.047 & .047 & ns \\
\hline \multirow{6}{*}{$\begin{array}{c}\text { Specific Cognitive Function --> Self- } \\
\text { care Confidence --> Self-care } \\
\text { Maintenance }\end{array}$} & Summary cognitive score & -.060 & -.228 & .109 & ns \\
\hline & Processing speed & .028 & -.016 & .073 & ns \\
\hline & Simple attention & -.067 & -.121 & -.014 & $*$ \\
\hline & Complex attention & -.019 & -.064 & .026 & ns \\
\hline & Working memory & .049 & .002 & .096 & $*$ \\
\hline & Short-term memory & .001 & -.024 & .025 & ns \\
\hline \multirow{6}{*}{$\begin{array}{c}\text { Specific Cognitive Function --> Self- } \\
\text { care Confidence --> Self-care } \\
\text { Maintenance --> Self-care } \\
\text { Management }\end{array}$} & Summary cognitive score & -.009 & -.034 & .016 & ns \\
\hline & Processing speed & .015 & -.009 & .040 & ns \\
\hline & Simple attention & -.037 & -.070 & -.004 & $*$ \\
\hline & Complex attention & -.010 & -.035 & .015 & ns \\
\hline & Working memory & .027 & -.001 & .054 & ns \\
\hline & Short-term memory & .001 & -.043 & .043 & ns \\
\hline
\end{tabular}

Note. ${ }^{*}=$ significant; $\mathrm{ns}=$ non-significant.

The table contains specific indirect effect (reported in the $1^{\text {st }}$ column), cognitive domain that identifies the model ( $2^{\text {nd }}$ column), standardized estimate of the effect ( $3^{\text {rd }}$ column), $90 \%$ confidence intervals based on 5,000 bootstrapping samples ( $4^{\text {th }}$ and $5^{\text {th }}$ column), and significance $\left(6^{\text {th }}\right.$ column). 